Jpn. J. Genet. (1981) 56, pp. 145-153

\title{
Storage effects on sex-chromosome losses induced by triethylene melamine (TEM) and ethyl methane- sulfonate (EMS) in Drosophila melanogaster
}

\author{
BY Makoto IKEBUCHI ${ }^{1)}$ and Yasuhiro TERANISHI ${ }^{2 j}$ \\ Zoological Laboratory, Faculty of Science, Hiroshima University, \\ Hiroshima 730
}

(Received May 27, 1980)

\begin{abstract}
Drosophila spermatozoa treated with triethylene melamine (TEM) or ethyl methanesulfonate (EMS) were stored in untreated females, and changes in the frequency of sex-chromosome losses were determined. In some experiments, an enhancing effect of storage on sex-chromosome losses was observed, while in other experiments the effect disappeared. The effect of storage was found to be dependent on the strains used. In the case of TEM, the effect was dose-dependent. At low doses the yield of sex-chromosome losses increased markedly after storage, while at high doses the enhancing effect disappeared. When enhancing effects were observed, the increase in yield after storage was marked for double marker losses (loss of both terminal markers on the doubly marked Y) than for single marker losses (loss of one of the two markers). These results suggest that sex-chromosome losses potentially respond to storage treatment, but the effect can be modified by some factors. The present findings are discussed in terms of potential break hypothesis.
\end{abstract}

\section{INTRODUCTION}

It is well known that when Drosophila spermatozoa treated with alkylating agents such as triethylene melamine (TEM), ethyleneimine, diepoxybutane, diethyl sulfate, and ethyl methanesulfonate (EMS) are stored in untreated females, the yield of translocations (Snyder 1963; Watson 1914, 1966; Ratnayake et al. 1967; Šram 1970a; Muñoz and Barnett 1977; Abrahamson et al. 1969; Ikebuchi and Nakao 1979; Ikebuchi 1980) increases strikingly. Storage effect has been also detected specifically for mutations associated with such chromosome breakage events as Minute mutations (Auerbach and Sonbati 1960), cytologically detectable chromosome rearrangements (Slizynska 1973) and dominant lethals (Ratnayake 1968; Šram 1970b; Ikebuchi and Nakao 1979), while a significant storage effect has not been observed for gene mutations such as visible (Brink 1970) and recessive lethal mutations (Snyder 1963;

1) Present address: Department of Experimental Radiology, Shiga University of Medical Science, Otsu, Shiga 520-21.

2) Present address: Department of Physiology, School of Medicine, Hiroshima University, Hiroshima 734. 
Watson 1964, 1966; Khan 1967; Ikebuchi 1980).

Sex-chromosome losses are assumed to arise from chromosome breakage events, although the mechanisms involved in such changes are not fully understood. If the storage effect is specific for breakage events, the frequency of sex-chromosome losses should increase after storage. An earlier study of Snyder (1963), however, has failed to show a significant increase in yield of TEM-induced sex-chromosome losses after storage treatment. If storage effects are truly lacking for sex-chromosome losses, the assumption that storage effect is specific for breakage events is questionable. The present study was undertaken to determine whether or not storage effect really exists for sex-chromosome losses. Furthermore, an attempt was made to clarify some aspects of the storage effect on sex-chromosome losses. The data presented in this report suggest that the yield of sex-chromosome losses induced by TEM and EMS is potentially affected by storage treatment, although the effects are modified by experimental conditions.

\section{MATERIALS AND METHODS}

The present experiments were divided into three series. In the first series, Drosophila melanogaster males had the constitution $y^{+} \mid B^{s} Y y^{+}$and the females were $I n(1) s c^{S 1 L} s c^{8 R}+d l-49, y$; $d p b w$; st $p^{p}$ (denoted as $J-244$ ) (For the genetic symbols, see Lindsley and Grell 1968). The $y / B^{s} Y y^{+}$males $(i-1)$ and the $C(1) D X, y f / B^{s} Y y^{+}$females [abbreviated as $C(1) D X$ ] were used in the second series. In the third series, $\operatorname{In}(1) s c^{81 L} s c^{8 R}+d l-49, B / B^{s} Y y^{+}$males $(f-96)$ were utilized in addition to $i-1$ males and $J-244$ females.

Two-day-old males were treated with TEM by injection technique in Series I (TEM was dissolved in $0.7 \%$ saline and the flies were injected with $0.2 \mu 1$ of TEM solution in the dorsal side of the abdomen by means of an Agla micrometer syringe) or by feeding technique in Series II and III [TEM and EMS were dissolved in $1 \%$ sucrose solution and they were fed for $24 \mathrm{~h}$ as described by Lewis and Bacher (1968)]. The treated males were mated individually with four virgin females on a medium for two days and then the males were discarded. The inseminated females were transferred to a fresh medium at twoday intervals to furnish 5 consecutive broods from the inseminated females. The medium was prepared by boiling a mixture of $1,100 \mathrm{ml}$ of water, $15 \mathrm{~g}$ of agar, $70 \mathrm{~g}$ of cornmeal, $15 \mathrm{~g}$ of dry yeast, $35 \mathrm{ml}$ of treacle, and $5 \mathrm{ml}$ of methyl$p$-benzoate $5 \%$ solution.

$\mathrm{F}_{1}$ offspring (males in Series I and III and females in Series II) were screened for three types of marker losses in the doubly marked $\mathrm{Y}$.

(1) Loss of both $B^{s}$ and $y^{+}$from Y (or loss of X): shown as $y$ males or $y f$ females.

(2) Loss of $B^{s}$ from Y: 
shown as wild type males or $f$ females.

(3) Loss of $y^{+}$from Y:

shown as $y B^{s}$ males or $y f B^{s}$ females.

In the present paper, loss of both $B^{s}$ and $y^{+}$was denoted as double marker loss. Types (2) and (3) were collectively designated as single marker losses and their data were pooled, since they exhibited a similar response to the storage treatment and were considered to be a similar type of aberrations. Although individuals for any of the above were easily detected as either completely-or mosaically-expressed changes, the mosaic-individuals were excluded from the present data and will be reported elsewhere.

It should be noted that any mutants recovered in Series II as double marker losses did not result from loss of the entire $\mathrm{X}$ or $\mathrm{Y}$ chromosome since the $C(1)$ $D X / O$ females are usually not viable probably due to their complete lack of $b b^{+}$gene (Lindsley and Grell 1968). In Series I and III, double marker losses could involve an entire loss of sex-chromosome as well as a partial one.

In Series $I, F_{1}$ males were individually backcrossed with $J$-244 virgin females to detect translocations involving chromosomes II, III and $\mathrm{Y}$ in $\mathrm{F}_{2}$. In Series II, the frequency of $\mathrm{X}$-linked recassive lethals was determined in $\mathrm{F}_{2}$ cultures to estimate the genetically effective dose; treated males were crossed in mass with $M-5$ virgin females for 3 days, and resulting $F_{1}$ virgin females were individually crossed with $M-5$ males.

Statistical significance of difference between the data obtained from two different samples (e.g., "unstored" vs. "stored") was tested using Kastenbaum and Bowman's tables (Kastenbaum and Bowman 1970) for the data on sexchromosome losses in Series I and $\chi^{2}$-test for translocations in Series I and sexchromosome losses in Series II and III.

\section{RESULTS}

In the first series of experiments, which was undertaken to follow the experiments of Snyder (1963), translocations and sex-chromosome losses induced in Drosophila sperm after injection with $1 \times 10^{-4} \mathrm{M}$ TEM were scored in broods$1,-3$ and -5 among 5 consecutive two-day broods from inseminated females (Table 1). It was found that the frequency of TEM-induced translocations increased markedly with extension of storage time. The frequency of sexchromosome losses was not affected significantly by the storage treatment, although the number of losses isolated in each experiment was small. After treatment with $2 \times 10^{-4} \mathrm{M}$ TEM, a similar result was obtained. These data confirm the results of Snyder (1963). It is thus concluded that under a certain experimental condition sex-chromosome losses are not subjected to the storage treatment.

The second series of experiments was carried out on a large scale in order 
Table 1. The effects of storage on the frequency of translocations and sex-chromosome losses induced by TEM $\left(1 \times 10^{-4} M\right.$; injection $)$ in Drosophila sperm [Data from Series $I]$

\begin{tabular}{|c|c|c|c|c|c|}
\hline \multirow{3}{*}{$\begin{array}{l}\text { Type of } \\
\text { changes }\end{array}$} & \multirow{3}{*}{$\begin{array}{l}\text { Expt. } \\
\text { No. }\end{array}$} & \multicolumn{3}{|c|}{ Frequency of changes (\%) } & \multirow{3}{*}{$\begin{array}{c}\text { Ratio of } \\
\text { brood-5/-1 }\end{array}$} \\
\hline & & \multirow{2}{*}{\begin{tabular}{|l} 
Unstored \\
Brood-1
\end{tabular}} & \multicolumn{2}{|c|}{ Stored } & \\
\hline & & & Brood-3 & Brood-5 & \\
\hline \multirow[t]{4}{*}{ Translocations } & 1 & $\begin{array}{l}1.11 \\
(10 / 902)\end{array}$ & $\begin{array}{l}3.57^{* * * *} \\
(31 / 869)\end{array}$ & $\begin{array}{l}6.90 * * * \\
(33 / 478)\end{array}$ & 6.2 \\
\hline & 2 & $\begin{array}{l}1.88 \\
(13 / 693)\end{array}$ & $\begin{array}{l}5.69 * * * \\
(26 / 457)\end{array}$ & $\begin{array}{l}6.88 * * * \\
(11 / 160)\end{array}$ & 3.7 \\
\hline & 3 & $\begin{array}{l}1.37 \\
(41 / 2984)\end{array}$ & $\begin{array}{l}4.01^{* * *} \\
(88 / 2192)\end{array}$ & $\begin{array}{l}5.48^{* * *} \\
(81 / 1479)\end{array}$ & 4.0 \\
\hline & Total & $\begin{array}{l}1.40 \\
(64 / 4579)\end{array}$ & $\begin{array}{l}4.12 * * * \\
(145 / 3518)\end{array}$ & $\begin{array}{l}5.90 * * * \\
(125 / 2117)\end{array}$ & 4.21 \\
\hline \multirow[t]{4}{*}{$\begin{array}{c}\text { Double marker } \\
\text { losses }\end{array}$} & 1 & $\begin{array}{l}0.18 \\
(3 / 1690)\end{array}$ & $\begin{array}{l}0.15 \\
(2 / 1344)\end{array}$ & $\overrightarrow{(0 / 748)}$ & 一 \\
\hline & 2 & $\begin{array}{l}0.32 \\
(3 / 935)\end{array}$ & $\begin{array}{l}0.53 \\
(4 / 755)\end{array}$ & $\begin{array}{l}0.93 \\
(2 / 216)\end{array}$ & 2.9 \\
\hline & 3 & $\begin{array}{l}0.32 \\
(12 / 3730)\end{array}$ & $\begin{array}{l}0.26 \\
(8 / 3019)\end{array}$ & $\begin{array}{l}0.42 \\
(7 / 1656)\end{array}$ & 1.3 \\
\hline & Total & $\begin{array}{l}0.28 \\
(18 / 6355)\end{array}$ & $\begin{array}{l}0.27 \\
(14 / 5118)\end{array}$ & $\begin{array}{l}0.34 \\
(9 / 2620)\end{array}$ & 1.21 \\
\hline \multirow[t]{4}{*}{$\begin{array}{c}\text { Single marker } \\
\text { losses }\end{array}$} & 1 & $\begin{array}{l}0.65 \\
(11 / 1690)\end{array}$ & $\begin{array}{l}0.52 \\
(7 / 1344)\end{array}$ & $\begin{array}{l}0.40 \\
(3 / 748)\end{array}$ & 0.6 \\
\hline & 2 & $\begin{array}{l}0.86 \\
(8 / 935)\end{array}$ & $\begin{array}{l}0.13 \\
(\mathbf{1} / 755)\end{array}$ & $\begin{array}{l}1.39 \\
(3 / 216)\end{array}$ & 1.6 \\
\hline & 3 & $\begin{array}{l}0.64 \\
(24 / 3730)\end{array}$ & $\begin{array}{l}0.26 \\
(8 / 3019)\end{array}$ & $\begin{array}{l}0.66 \\
(11 / 1656)\end{array}$ & 1.0 \\
\hline & Total & $\begin{array}{l}0.68 \\
(43 / 6355)\end{array}$ & $\begin{array}{l}0.31 \\
(16 / 5118)\end{array}$ & $\begin{array}{l}0.65 \\
(17 / 2620)\end{array}$ & 0.96 \\
\hline
\end{tabular}

*** Significant at the $0.1 \%$ level from brood-1.

to determine whether or not storage effects are truly lacking for sex-chromosome losses. Some experimental conditions were changed. Feeding technique was used to treat simultaneously a large number of flies. Change of strains would permit us to detect different types of sex-chromosome losses from Series I. EMS was tested as well as TEM. Two experiments were run at each concentration (with the exception of three experiments at the lowest dose of EMS), and the data were pooled since the yields of sex-chromosome losses did not differ significantly between two experiments and responded in a similar fashion to the storage treatment. Furthermore, the number of $F_{1}$ females scored or mutants recovered in broods- 1 and -2 was summed up together as "unstored samples" and that in broods-3, -5 as "stored samples". As can be seen in Table 2, at low doses of TEM $\left(0.5\right.$ and $\left.2.5 \times 10^{-5} \mathrm{M}\right)$ the frequency of double marker losses increased significantly after storage of sperm. Single marker losses also responded to the storage treatment at the lowest dose $\mathbf{0 . 5}$ $\left.\times 10^{-5} \mathrm{M}\right)$. At high doses, however, the storage effect disappeared. This indi- 
Table 2. The effects of storage on the frequency of sex-chromosome losses induced by TEM $\left(0.5-10 \times 10^{-5} M\right)$ and EMS $\left(2.5-10 \times 10^{-8} M\right)$ in Drosophila sperm [Data from Series II]

\begin{tabular}{|c|c|c|c|c|c|c|}
\hline \multirow{2}{*}{ Mutagen } & \multirow{2}{*}{$\begin{array}{c}\text { Type of } \\
\text { losses }\end{array}$} & \multirow{2}{*}{$\begin{array}{c}\text { Conc. } \\
\left(\times 10^{-5} \mathrm{M}\right)\end{array}$} & \multirow{2}{*}{$\begin{array}{c}\% \\
\text { lethals }\end{array}$} & \multicolumn{2}{|c|}{ Frequency of losses $(\%)$} & \multirow{2}{*}{$\begin{array}{l}\text { Ratio of } \\
\text { Stored/ } \\
\text { Unstored }\end{array}$} \\
\hline & & & & Unstored $^{a}$ & Stored ${ }^{b}$ & \\
\hline \multirow[t]{8}{*}{ TEM } & \multirow{4}{*}{$\begin{array}{l}\text { Double } \\
\text { marker } \\
\text { losses }\end{array}$} & 0 & n. t.c & $\overline{(0 / 16348)}$ & $\begin{array}{l}0.007 \\
(1 / 13972)\end{array}$ & - \\
\hline & & 0.5 & $\begin{array}{l}2.68 \\
(43 / 1602)\end{array}$ & $\begin{array}{l}0.026 \\
(8 / 30272)\end{array}$ & $\begin{array}{l}0.096^{* * *} \\
(27 / 28075)\end{array}$ & 3.69 \\
\hline & & 2.5 & $\begin{array}{l}4.79 \\
(67 / 1398)\end{array}$ & $\begin{array}{l}0.061 \\
(12 / 19596)\end{array}$ & $\begin{array}{l}0.222 * * * \\
(40 / 18035)\end{array}$ & 3.64 \\
\hline & & 10 & $\begin{array}{l}8.02 \\
(99 / 1234)\end{array}$ & $\begin{array}{l}0.272 \\
(33 / 12148)\end{array}$ & $\begin{array}{l}0.392 \\
(44 / 11211)\end{array}$ & 1.44 \\
\hline & \multirow{4}{*}{$\begin{array}{l}\text { Single } \\
\text { marker } \\
\text { losses }\end{array}$} & 0 & n. $t$. & $\begin{array}{l}0.080 \\
(13 / 16348)\end{array}$ & $\begin{array}{l}0.050 \\
(7 / 13972)\end{array}$ & 0.63 \\
\hline & & 0.5 & $\begin{array}{l}2.68 \\
(43 / 1602)\end{array}$ & $\begin{array}{l}0.092 \\
(28 / 30272)\end{array}$ & $\begin{array}{l}0.189 * * \\
(53 / 28075)\end{array}$ & 2.05 \\
\hline & & 2.5 & $\begin{array}{l}4.79 \\
(67 / 1398)\end{array}$ & $\begin{array}{l}0.316 \\
(62 / 19596)\end{array}$ & $\begin{array}{l}0.250 \\
(45 / 18035)\end{array}$ & 0.79 \\
\hline & & 10 & $\begin{array}{l}8.02 \\
(99 / 1234)\end{array}$ & $\begin{array}{l}0.354 \\
(43 / 12148)\end{array}$ & $\begin{array}{l}0.437 \\
(49 / 11211)\end{array}$ & 1.23 \\
\hline \multirow[t]{6}{*}{ EMS } & \multirow{3}{*}{$\begin{array}{l}\text { Double } \\
\text { marker } \\
\text { losses }\end{array}$} & 250 & $\begin{array}{l}17.05 \\
(104 / 610)\end{array}$ & $\begin{array}{l}0.011 \\
(5 / 44161)\end{array}$ & $\begin{array}{l}0.047^{*} \\
(18 / 38271)\end{array}$ & 4.27 \\
\hline & & 500 & $\begin{array}{l}31.30 \\
(190 / 607)\end{array}$ & $\begin{array}{l}0.033 \\
(9 / 27531)\end{array}$ & $\begin{array}{l}0.159 * * * \\
(22 / 13860)\end{array}$ & 4.82 \\
\hline & & 1000 & $\begin{array}{l}39.64 \\
(222 / 560)\end{array}$ & $\begin{array}{l}0.100 \\
(12 / 12000)\end{array}$ & $\begin{array}{l}0.406^{* * *} \\
(20 / 4931)\end{array}$ & 4.06 \\
\hline & \multirow{3}{*}{$\begin{array}{l}\text { Single } \\
\text { marker } \\
\text { losses }\end{array}$} & 250 & $\begin{array}{l}17.05 \\
(104 / 610)\end{array}$ & $\begin{array}{l}0.115 \\
(51 / 44161)\end{array}$ & $\begin{array}{l}0.178^{*} \\
(68 / 38271)\end{array}$ & 1.55 \\
\hline & & 500 & $\begin{array}{l}31.30 \\
(190 / 607)\end{array}$ & $\begin{array}{l}0.225 \\
(62 / 27531)\end{array}$ & $\begin{array}{l}0.325 \\
(45 / 13860)\end{array}$ & 1.44 \\
\hline & & 1000 & $\begin{array}{l}39.64 \\
(222 / 560)\end{array}$ & $\begin{array}{l}0.333 \\
(40 / 12000)\end{array}$ & $\begin{array}{l}0.608^{*} \\
(30 / 4931)\end{array}$ & 1.83 \\
\hline
\end{tabular}

a Brood $-1+2$.

b Brood $-3+4+5$.

c Not tested.

* Significant at the 5\% level from the unstored samples.

** Significant at the 1\% level from the unstored samples.

*** Significant at the $0.1 \%$ level from the unstored samples.

cates that the storage effects on TEM-induced sex-chromosome losses are dosedependent. In addition, it was suggested that the storage effect depends on the types of losses. At the lowest doses of TEM, increase in their yields after storage was more evident for double marker losses than single marker losses.

In the case of EMS-induced sex-chromosome losses, the ratios of "stored" to "unstored" samples were fairly constant at the tested doses (4.1-4.8 and 1.4-1.8 for double and single marker losses, respectively). This indicates that storage effects on both double and single marker losses induced by EMS are 
Table 3. The effects of storage on the frequency of sex-chromosome losses induced by EMS in Drosophila sperm in two different crosses

[Data from iseries.III]

\begin{tabular}{|c|c|c|c|c|}
\hline \multirow{2}{*}{$\begin{array}{l}\text { Crosses } \\
\left(\begin{array}{l}1 \\
\times\end{array} \text { 우) }\right.\end{array}$} & \multirow{2}{*}{ Type of losses } & \multicolumn{2}{|c|}{ Frequency of losses (\%) } & \multirow{2}{*}{$\begin{array}{c}\text { Ratio of } \\
\text { Stored/ } \\
\text { Unstored }\end{array}$} \\
\hline & & Unstored $^{\mathrm{a}}$ & Stored $b$ & \\
\hline \multirow[t]{2}{*}{$i-1^{\mathrm{c}} \times J-244^{\mathrm{d}}$} & Double marker losses & $\begin{array}{l}0.167 \\
(15 / 8990)\end{array}$ & $\begin{array}{l}0.257 \\
(21 / 8170)\end{array}$ & 1.54 \\
\hline & Single marker losses & $\begin{array}{l}0.111 \\
(10 / 8990)\end{array}$ & $\begin{array}{l}0.196 \\
(16 / 8170)\end{array}$ & 1.77 \\
\hline \multirow[t]{2}{*}{$f-96^{\mathrm{e}} \times J-244$} & Double marker losses & $\begin{array}{l}0.661 \\
(51 / 7718)\end{array}$ & $\begin{array}{l}0.866 \\
(105 / 12120)\end{array}$ & 1.31 \\
\hline & Single marker losses & $\begin{array}{l}0.052 \\
(4 / 7718)\end{array}$ & $\begin{array}{l}0.165^{*} \\
(20 / 12120)\end{array}$ & 3.17 \\
\hline
\end{tabular}

a Brood-1+2.

b Brood-3+4+5.

c $y / B^{s} Y y^{+}$.

d $\operatorname{In}(1) s c^{S 1 L} s c^{8 R}+d l-49, y ; d p b w ; s t p^{p}$.

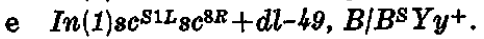

* Significant at the $5 \%$ level from the unstored samples.

dose-independent. Comparison of the ratios between double and single marker losses demonstrated a strong dependency of storage effect on types of sexchromosome losses. At the doses tested, the ratios for double marker losses were always higher than those for single marker losses.

In Series III, a possibility of strain-dependency of storage effect was tested under the same experimental conditions as Series II. For this test EMS was used as a mutagen, since storage effect with EMS was dose-independent and more distinct than that with TEM (Series II). Table 3 shows that effect of storage on EMS-induced double marker losses disappeared when, instead of $C(1) D X$ females, $J-244$ females were crossed with $i-1$ or $f-96$ males, indicating a strain-dependency of storage effect. The extent of increase in single marker losses during storage was comparable with or more evident than that found in Series II. It should be pointed out that, in contrast to Series II, the yield of double marker losses is relatively higher than the yield of single marker. losses, especially in the cross of $f-96$ males with $J-244$ females.

\section{DISCUSSION}

The present results reveal that the responses of sex-chromosome losses to storage treatment vary depending on the types of losses recovered, strains, mutagens and doses used. Nevertheless, the fact that sex-chromosome losess, especially double marker losses, exhibited a storage effect in experiments of Series II can be interpreted to indicate that sex-chromosome losses induced by TEM or EMS are potentially subjected to storage treatment, but modified by 
experimental conditions. We assume that the present data do not conflict with the concept that storage effect is specific for breakage events and the effect on sex-chromosome losses can be explained in terms of "potential break hypothesis".

Auerbach (1949) and Slizynska (1973) have proposed that storage effects in Drosophila sperm are due to a delay, during storage, in converting potential breaks to open (true) breaks. On this potential break hypothesis, the apparent loss of storage effect on sex-chromosome losses at high doses in Series II is interpreted that application of high dose of TEM accelerates the process of conversion from potential breaks to open breaks and shortens the time of delay in conversion so that increase in the yield of sex-chromosome losses terminates before storing sperm. Also, on the same ground, the finding in Series II that increase in their yields after storage was more evident for double marker losses than single marker losses can be interpreted that chromosome breaks resulting in single marker losses tend to open earlier than those leading to double marker losses. The finding of strain-dependency of storage effect (Tables 2 and 3) suggests that timing of conversion of potential to open breaks can be shifted by using different strains.

Inspection of the data in Tables 2 and 3 shows that, when distinct storage effect appeared, the yield of sex-chromosome losses in unstored samples was low (less than $0.1 \%$ ) relatively to other cases where storage effect disappeared. This low yield in unstored samples should reflect the situation that most of the breaks remained potential before storing sperm.

A differential storage effect between single and double marker losses was found in Series II. This may be due to the difference in their induction mechanisms. Single marker losses are derived from deletions involving a region of one of the two terminal markers of $Y$ chromosome. In contrast, double marker losses recovered in Series II are considered to arise from multi-break aberrations, a type of change similar to translocations, such as interarm exchanges of $\mathrm{Y}$ resulting in ring chromosomes (Oster 1964; Traut et al. 1970; Falk and Jacoby 1975) since their drastic response to storage treatment was comparable with that of translocations induced by TEM (Series I) and EMS (Ikebuchi and Nakao 1969).

The finding of a differential response of different strains to storage treatment in the induction of sex-chromosome losses (Tables 2 and 3) can be also explained to be due to a difference in underlying mechanisms of sex-chromosome losses. As described in Materials and Methods, loss of entire X or $\mathrm{Y}$ chromosome cannot be recovered from $C(1) D X$ females, while both entire and partial losses can be recovered from $J-244$ females. The relatively higher yield of double marker losses than that of single marker losses in Series III would reflect involvement of entire sex-chromosome loss in addition to partial one among double marker losses recovered from $J$-244 females. It is suspect- 
ed that loss of entire $\mathrm{X}$ or $\mathrm{Y}$ may be a type which is refractory to the storage treatment and the majority of double marker losses recovered in $J-244$ females was loss of entire $\mathrm{X}$ or $\mathrm{Y}$ chromosome. On the other hand, partial losses expressed as double marker losses in Series II may be subjected drastically to the storage treatment. Thus, we have assumed that most of the complexity of storage effect on sex-chromosome losses may reflect a complexity of mechanisms of sex-chromosome losses. Further experiments are, however, necessary in ascertaining the mechanisms involved in the induction of sex-chromosome losses, before interpretation on the difference in storage effect among strains and types of losses can be made on a solid footing.

The authors wish to express their gratitude to $\mathrm{Dr}$. Y. Nakao for his guidance and encouragement in the course of the present study.

\section{REFERENCES}

Abrahamson, S., Kiriazis, W. C. and Sabol, E. M. (1969) A storage effect of ethyl methanesulfonate (EMS) on the induction of translocations in Drosophila sperm. Drosophila In form. Serv. 44, 110-111.

Auerbach, C. (1949) Chemical induction of mutations. Hereditas (Suppl.), 128-147.

Auerbach, C., and Sonbati, E. M. (1960) Sensitivity of Drosophila testis to the mutagenic action of mustard gas. $Z$. Vererbungslehre 91, 237-252.

BRINK, N. G. (1970) Complete and mosaic visible mutations produced by ethyl methanesulfonate in Drosophila melanogaster. Mutation Res. 10, 227-236.

FALK, R. and JACOBY, M. (1975) Partial losses of sex chromosomes induced by X-rays in spermatozoa of Drosophila melanogaster. Mutation Res. 29, 397-406.

IKEBUCHI, M. (1980) Relative frequency of translocations to sex-linked recessive lethals induced by ethyl methanesulfonate (EMS) in spermatozoa of Drosophila, with special reference to the storage effect. J. Sci. Hiroshima Univ., Ser. B, Div. 1. (In the Press.)

IKEBUCHI, M. and NAKAO, Y. (1979) Storage effects on translocations and dominant lethals induced by ethyl methanesulfonate (EMS) in Drosophila melanogaster. Jpn. J. Genet. 54, 133137.

Kastenbaum, M. A. and Bowman K. O. (1970) Tables for determining the statistical significance of mutation frequencies. Mutation Res. 9, 527-549.

KHAN, A. H. (1969) Effect of storage of alkylated chromosomes on the mutagenic effectiveness of monofunetional alkylation. Mutation Res. 8, 565-571.

LEWIS, E. B. and BACHER, (1968) Method of feeding ethyl methanesulfonate (EMS) to Drosophila males. Drosophila In form. Serv. 43, 193.

LiNDSLEY, D. and GRELL, E. H. (1968) Genetic variations of Drosophila melanogaster. Carnegie Inst. Wash. Pub. No. 627.

MuÑoz, E. R. and BARNETr, B. M. (1977) II-III translocations induced by diethyl sulfate in mature sperm of Drosophila melanogaster. Mutation Res. 45, 355-357.

OSTER, I. I. (1964) Filicidal Y chromosomes. Genetics 50, 274.

RATNAYAKE, W. E. (1968) Effects of storage on dominant lethals induced by alkylating agents (triethylene melamine and ethylenimine). Mutation Res. 5, 271-278.

Ratnayake, W. E., Strachan, C. and Auerbach, C. (1967) Genetical analysis of the storage effect of triethylene melamine (TEM) on chromosome breakage in Dorosophila. Mutation Res. 4, 380-381.

SLIZYNSKA, H. (1973) Cytological analysis of storage effects on various types of complete and mosaic change induced in Drosophila chromosomes by some chemical mutagens. Mutation Res. 19, 199-213. 
SNYder, L. A. (1963) Evidence of an essential difference between point mutations and chromosome breaks induced by triethylene melamine in Drosophila spermatozoa. $Z$. Vererbungslehre 94, 182-189.

ŠAM, R. J. (1970a) The effect of storage on the frequency of translocations in Drosophila melanogaster. Mutation Res. 9, 243-244.

SRAM, R. J. (1970b) The effect of storage on the frequency of dominant lethals in Drosophila melanogaster. Molec. Gen. Genetics 106, 286-288.

Traut, H., Scheid, W. and Wind, H. (1970) Partial and total sex-chromosome loss induced by $\mathrm{X}$-rays in mature spermatozoa of Drosophila melanogaster. Mutation Res. 9, 489-499.

WATSON, W. A. F. (1964) Evidence of an essential difference between the genetical effects of mono- and bi-functional alkylating agents. $Z$. Vererbungslehre 95, 374-378.

WATSON, W. A. F. (1966) Further evidence of an essential difference between the genetical effects of mono- and bi-functional alkylating agents. Mutation Res. 3, 455-457. 